\title{
La conservación neoliberal: otra cara de la economía verde. Estudio de caso en el Corredor Ecológico Llanganates Sangay, Ecuador
}

\section{Neoliberal Conservation: Another Face of the Green Economy. A Case Study in the Llanganates Sangay Ecological Corridor, Ecuador}

Oscar Miguel Luna Alvarado

\section{Resumen}

A partir del estudio de caso en el Corredor Ecológico Llanganates Sangay, se elabora una caracterización del proceso de compra de tierras para la creación de áreas protegidas privadas en el marco del modelo de la conservación neoliberal y de la conservación estricta. El argumento de este estudio es que la conservación neoliberal, al contrario de su discurso ganar-ganar, genera procesos de despojo, desplazamiento y exclusión de poblaciones locales, en beneficio de grandes empresas. Los procesos de despojo no ocurren necesariamente mediante formas tradicionales violentas, sino a través de mecanismos cada vez más sofisticados como la compra de tierras. En este contexto, aunque la conservación neoliberal se presenta como un mecanismo para solucionar las problemáticas ambientales actuales y alcanzar el desarrollo sostenible, en realidad puede ser usada para la expansión de la economía verde.

Palabras clave: áreas protegidas; economía verde; desarrollo sostenible; conservación neoliberal; conservación estricta;

\section{Abstract}

Based on a case study in the Llanganates Sangay Ecological Corridor, this research analyzes the characteristics of land acquisition for the creation of private protected areas within the framework of the neoliberal conservation and strict conservation model. This study is based on the argument

\footnotetext{
I Doctorante del programa de Desarrollo Territorial de la Facultad Latinoamericana de Ciencias Sociales (Flacso), Ecuador. Maestría en Estudios Latinoamericanos, Universidad Andina Simón Bolívar, Ecuador. Líneas de interés: ecología política, conservación, áreas protegidas, desarrollo territorial, capitalismo verde. ORCID: https://orcid.org/0000-0002-0069-6381. Correo electrónico: oscarlunatie@ gmail.com
} 
that contrary to its purported win-win approach, neoliberal conservation leads to processes of dispossession, displacement, and exclusion of local populations in the interest of large companies. Dispossession processes do not necessarily happen in traditionally violent ways but through increasingly sophisticated mechanisms, such as land acquisition. In this context, even though neoliberal conservation is presented as a mechanism for solving current environmental issues and achieving sustainable development, it can in fact be used for the expansion of the green economy.

Keywords: protected areas; green economy; sustainable development; neoliberal conservation; strict conservation;

\section{Introducción}

Diversas civilizaciones a lo largo de la historia han realizado prácticas de conservación (Meléndez, 2010; Hernández, 2011; Oviedo, 2013). Puede afirmarse que las prácticas de conservación no son fenómenos exclusivos de la modernidad: se remontan a tiempos ancestrales, no obstante, la conservación que conocemos actualmente es producto de la sociedad moderna y deriva de la división entre naturaleza y sociedad (Durand, 2017).

Un caso concreto que reproduce la visión moderna y dominante de conservación es el de la Fundación estudiada, ${ }^{1}$ una Organización No Gubernamental (ONG) ecuatoriana que con financiamiento internacional ha implementado la compra de tierras para la creación de áreas protegidas privadas como principal estrategia de conservación del Corredor Ecológico Llanganates Sangay (CELS). La ONG y su equipo de investigadores han realizado importantes estudios de flora y fauna en las zonas que conservan, muchos de los cuales son de relevancia para la ciencia. El alcance de esta investigación se centra en los impactos socioambientales que genera la fundación, mas no en sus aportes a la investigación biológica.

El modelo propuesto por la Fundación se enmarca en un contexto global que presenta a la conservación como un mecanismo para solucionar las problemáticas ambientales actuales ${ }^{2}$ y alcanzar el desarrollo sostenible; sin embargo, varios estudios han demostrado que la conservación per se no necesariamente contribuye a la sostenibilidad, sino que puede ser usada como mecanismo para la expansión del capitalismo (Igoe y Brockington, 2007; Brockington et al., 2008; Brockington y Duffy, 2011; Durand, 2017; Luna, 2019). En nombre de la conservación se han generado procesos de despojo, desplazamientos de campesinos, privatización, entre otras consecuencias adversas (D’Amico, 2015).

\footnotetext{
${ }^{1}$ Se mantiene en anonimato el nombre de la organización. En el resto de este artículo se denominará como Fundación u ONG.

${ }^{2}$ Como la pérdida de diversidad genética, la erosión de los suelos, la pérdida de bosques, la contaminación de fuentes de agua dulce, el cambio climático, entre otros.
} 
Si bien estos procesos han sido estudiados en el marco de la conservación neoliberal, son pocos los estudios que han profundizado en las formas sobre cómo operan. Esta investigación analiza la compra de tierras para la creación de áreas protegidas privadas como uno de los mecanismos de la conservación neoliberal. En este sentido, la pregunta de investigación planteada es: ¿cuáles son las principales características del proceso de compra de tierras para la creación de áreas protegidas privadas en el caso de la Fundación estudiada?

La metodología aplicada en esta investigación es el estudio de caso, el cual se distingue por tener tres características principales (Yin, 2003): integra múltiples variables de interés, se basa en diversas fuentes de evidencia que convergen de forma triangular y se beneficia de proposiciones teóricas desarrolladas previamente para guiar la recolección y análisis de datos. La unidad de análisis seleccionada (el Corredor Ecológico Llanganates Sangay, CELS) cumple con estas características, lo cual justifica la pertinencia del estudio de caso como estrategia metodológica.

En cuanto al proceso de investigación, en primer lugar, se revisaron fuentes bibliográficas primarias y secundarias generadas sobre el caso de estudio. En segundo lugar, se realizó un trabajo de campo en el cantón Baños de Agua Santa en tres periodos: mayo de 2016, en donde se hizo un reconocimiento del área analizada a partir de la observación participante y un mapeo de actores estratégicos del CELS; noviembre de 2017, que consistió en un levantamiento de la información en el territorio, así como entrevistas a actores estratégicos; abril de 2018, con entrevistas complementarias para corroborar y afinar la información colectada. Por último, se analizaron los datos encontrados vinculando la teoría con la evidencia empírica con el fin de construir las conclusiones del estudio.

La investigación se presenta en tres secciones. En la primera sección se expone el marco teórico sobre el cual se sustenta la investigación. Posteriormente se describe el caso de estudio y se analiza la información levantada en campo a partir del marco teórico desarrollado. Por último, se presentan las conclusiones.

\section{Conservación moderna y desarrollo sostenible}

Actualmente, la definición más aceptada de conservación es la propuesta en la Estrategia Mundial para la Conservación de 1980 (Hernández, 2011), elaborada por la Unión Internacional de la Conservación de la Naturaleza y Recursos Naturales (UICN), el Fondo Mundial para la Vida Silvestre (WWF) y el Programa de las Naciones Unidas para el Medio Ambiente (PNUMA). Esta estrategia define a la conservación como "la gestión de la utilización de la biósfera por el ser humano, de tal suerte que produzca el mayor y sostenido beneficio para las generaciones actuales, pero que mantenga su potencialidad para satisfacer las necesidades y las aspiraciones de las generaciones futuras" (UICN, 1980: s.p.). 
Esta definición manifiesta dos características principales; por un lado, busca posicionar la conservación como eje central para el desarrollo sostenible (Giménez, 2010); por otro lado, parte desde una perspectiva antropocéntrica y dualista que mira a la naturaleza como un recurso exterior al ser humano al cual éste puede controlar y dominar para su beneficio. Esta visión dominante de conservación fue construida en el marco de las primeras versiones de desarrollo sostenible en los años ochenta (Giménez, 2010). Para Naredo (1996), el desarrollo sostenible sirvió de puente para reconciliar a los desarrollistas con los ambientalistas, puesto que el concepto incorpora el crecimiento económico, pero con un rostro ambiental.

A pesar de que el desarrollo sostenible tuvo una aceptación generalizada, también fue objeto de duras críticas por parte de activistas y académicos, quienes argumentaban que, dado que son términos contradictorios, el desarrollo y la sostenibilidad no pueden ir de la mano. El concepto sigue pretendiendo el crecimiento económico ilimitado en un planeta que tiene recursos naturales finitos. Estos cuestionamientos que evidenciaban profundas contradicciones del discurso de desarrollo sostenible, junto con su uso indiscriminado por parte de diversos actores para diferentes propósitos, generaron un desgaste ideológico y vaciamiento de sentido del concepto (Naredo, 1996; Moreno, 2013).

La economía verde nace a mediados de los noventa presentándose como un remedio para superar la crisis ecológica mediante una fórmula de ganar-ganar que incorpora la dimensión social, ecológica y económica (Brand y Wissen, 2013). Se propuso como un concepto renovado que sustituye al término de desarrollo sostenible (Moreno, 2013). Este estudio entiende a la economía verde como el conjunto de lógicas y mecanismos basados en el mercado que se aplican sistemáticamente en el manejo y la gobernanza ambiental (Corson et al., 2013). Por tanto, la economía verde es un proyecto en construcción, que se ha posicionado en diferentes espacios en los últimos años (Brand, 2012a). Esta pretende traducir el desarrollo sostenible en prácticas disciplinadas por mecanismos y lógicas de mercado que requieren de: "nuevas formas de cálculo, medición y monitoreo de la naturaleza; nuevas relaciones sociales entre inversionistas, políticos, burócratas, técnicos y activistas; nuevos circuitos para la transmisión de capital a nuevos productos básicos y empresas; y nuevas prácticas de representación con las que se pueden incorporar nuevos actores en estos proceso" (Corson et al., 2013: 5).

La economía verde se presenta como una vía atractiva para diferentes sectores de la población frente a las problemáticas ambientales actuales; no obstante, como muestran Brand y Wissen (2013), la mayoría de los estudios relacionados con la economía verde hacen un análisis superficial de las problemáticas ambientales sin incorporar una visión conjunta del problema, ni abordar temas de fondo como las relaciones de poder dentro de la sociedad capitalista (Lander, 2011). 


\section{Ambiente}

De hecho, en lugar de combatir la crisis ambiental, la economía verde genera conflictos socioambientales. Varios estudios realizados alrededor del mundo demuestran que la economía verde se basa en acaparamientos verdes (green grabbing en inglés) (Corson et al., 2013). Fairhead et al. (2012: 238) señalan que el acaparamiento verde, entendido como la apropiación de tierras y recursos ambientales, es un proceso creciente a nivel mundial. "La 'apropiación' implica la transferencia de la propiedad, los derechos de uso y el control sobre los recursos que una vez fueron de propiedad pública o privada de los pobres (o de todos, incluso de los pobres), en manos de los poderosos".

Para estos autores, el acaparamiento verde no siempre implica la enajenación total de la tierra por parte de los afectados, sino que conlleva la reestructuración de las reglas y la autoridad sobre el acceso, el uso y la gestión de los recursos, en las relaciones laborales y en las relaciones humano-ecológicas, que pueden tener efectos profundamente alienantes (Fairhead et al., 2012). Asimismo, el impacto que genera el acaparamiento verde en algunos casos se manifiesta a través de formas tradicionales violentas (expulsión forzosa). Sin embargo, en otros casos, existen nuevas formas de apropiación de la naturaleza a través de mecanismos sofisticados como la compra de tierras (caso estudiado en este artículo); en estos procesos la línea que separa los ganadores y los perdedores es menos clara.

Autores como Moreno (2013) y Brand (2012b) plantean que la economía verde es una narrativa unificadora en favor de una nueva base de acumulación en el sistema capitalista, que pretende incorporar diferentes aspectos de la naturaleza antes no considerados como mercancías, por medio de una valorización monetaria. Moreno (2013) advierte que más allá del plano retórico, la economía verde avanza, en la práctica, hacia los ámbitos más diversos de la vida. La conservación es uno de los campos que se insertan dentro de la lógica de la economía verde. Desde este planteamiento, en el próximo apartado se aborda la relación entre la denominada conservación neoliberal y la economía verde.

\section{Conservación neoliberal: una estrategia enmarcada en la economía verde}

A finales de la década de los ochenta, se produjo en América Latina un giro hacia el neoliberalismo (Durand, 2014). Dicho modelo condujo a las políticas de la región, incluidas las del sector ambiental, a plantearse nuevas pautas para la acumulación. March (2013: 139) señala que entrando al siglo XXI, "esferas de la naturaleza que estaban fuera del mercado son incorporadas en las lógicas de acumulación capitalista". Se concibieron nuevas políticas ambientales desde el cuerpo conceptual del neoliberalismo ambiental que no contradecían los principios básicos del crecimiento económico (Gudynas, 1993). El neoliberalismo, en términos ambientales, conlleva la privatización y la mercantilización de la naturaleza, como se examina más adelante, donde el Estado tiene un papel fundamental para garantizar dichos procesos (Budds y McGranahan, 2003). 
La neoliberalización del medio ambiente se despliega a través de los procesos de privatización, desregulación, re-regulación, mercantilización; por tanto, es necesario abordar cada uno de estos procesos. En primer lugar, para Castree (2008) la privatización conlleva la asignación de derechos de propiedad privada a fenómenos sociales y ambientales que antes eran propiedad del Estado, de la comunidad, o que no tenían propietarios. March (2013: 142) plantea que la privatización es un momento clave de la neoliberalización del medio ambiente, ya que permite materializar el proyecto neoliberal. El Estado desempeña un papel clave en el proceso de privatización: "en un principio para organizar e iniciar el proceso y, posteriormente, en el seguimiento y el establecimiento de marcos postregulatorios" que permiten consolidar la propiedad privada.

En segundo lugar, la neoliberalización del medio ambiente conlleva más que un proceso de desregulación uno de re-regulación. Para Castree (2008), la re-regulación se basa en la intervención del Estado para facilitar la privatización y la mercantilización de ámbitos de la vida social y ambiental. En tercer lugar, la mercantilización de la naturaleza puede ser entendida como el proceso mediante el cual el capitalismo penetra en la naturaleza, incorporándola al libre mercado bajo las lógicas de la economía neoclásica (Cruz et al., 2018). Para March (2013: 145), "el momento central de la neoliberalización de la naturaleza es, probablemente, la mercantilización de ésta última”. El proceso de mercantilización de la naturaleza no es homogéneo, sino que ocurre de diferentes formas (Castree, 2003), por ejemplo, a través de bancos de conservación, propiedad intelectual, entre otros (Cruz et al., 2018). Desde esta perspectiva, se concibe a la naturaleza como una mercancía que debe ser ingresada al mercado.

El neoliberalismo opera de diferentes formas a partir del contexto en el que se despliega, por tanto, no es un fenómeno homogéneo. Considerando este planteamiento, es necesario estudiar las lógicas neoliberales dentro del campo de la conservación, también conocida como conservación neoliberal (Durand, 2014). Esta autora señala que la conservación neoliberal conlleva la transformación de individuos o grupos familiares en pequeños empresarios, capaces de utilizar su capital natural para producir nuevas mercancías a través de la promoción de la conservación. Acorde con la lógica de la economía verde, la conservación neoliberal "busca conciliar la supuesta eficiencia del mercado con los objetivos de preservación ambiental y supone que la naturaleza sólo puede ser preservada si se asigna un valor económico a sus componentes y si su conservación reditúa lucros concretos a los dueños de los recursos" (Durand, 2014: 193). La rentabilidad de la naturaleza es un eje central de esta visión; aquellos recursos, especies, ecosistemas, paisajes, que no son rentables quedan excluidos de la conservación.

La conservación neoliberal maneja un discurso atractivo para diferentes sectores. Según Igoe y Brockington (2007: 434), ésta promete generar recursos económicos, aumentar la demo- 


\section{Ambiente}

cracia y la participación ciudadana (menos restricciones del Estado), proteger a las comunidades resguardando su derecho a la propiedad privada e impulsando emprendimientos basados en la conservación (comercio verde, ecoturismo, etcétera) y, sobre todo, promete ser "una solución simple a problemas complejos y difíciles". En términos prácticos, la conservación neoliberal opera a través de diferentes mecanismos de conservación. Esta investigación no pretende abordar cada uno de los mecanismos, sino analizar la compra de tierras para la creación de áreas protegidas privadas. Este mecanismo, contrariamente a su discurso positivo (modelo ganar-ganar), en realidad suele generar procesos de desplazamiento, exclusión y despojo de las poblaciones locales.

La conservación neoliberal, a través de la creación de un área protegida u otros mecanismos de conservación, puede despojar a la población local de la tierra tan eficazmente como un proyecto extractivista (Büscher et al., 2012). Estos procesos de despojo no ocurren necesariamente de formas tradicionales violentas, sino a través de mecanismos cada vez más sofisticados como la compra de tierras, el ecoturismo, los productos financieros, entre otros. Como resultado, millones de personas (muchas en condiciones vulnerables) alrededor del mundo han sido desplazadas para dar espacio a la creación de áreas protegidas (Luna, 2019). Para Brockington e Igoe (2006), diversas ONG han desempeñado un papel activo en la creación de áreas protegidas que excluyen a la población local y generan procesos de desplazamiento. El discurso legitimador que se encuentra detrás de los procesos de despojo relacionados con la conservación, generalmente, considera a grupos subalternos como los principales agentes de la pérdida de biodiversidad.

Esta investigación sostiene que la conservación neoliberal es la economía verde aplicada de forma concreta en el campo de la conservación de la biodiversidad y, por tanto, que ambas parten de las mismas premisas. Ambos enfoques reconfiguran el papel del Estado en función del fortalecimiento del mercado. La economía verde y la conservación neoliberal necesitan del Estado, pues su implementación depende de un marco jurídico que brinde seguridad y validez a los contratos e inversiones (Moreno, 2013). Este marco jurídico debe alinearse al fortalecimiento del mercado, habilitar y garantizar las diversas transacciones a nivel mundial como en el caso de los mercados de carbono.

Ambas lógicas se fundamentan en un discurso de ganar-ganar: todos los sectores salen beneficiados. Sin embargo, ambas se presentan como soluciones ante las problemáticas ambientales, sin abordar problemas estructurales de fondo; las dos parten desde una ontología dualista; y en ambas prevalece una valoración monetaria de la naturaleza que excluye otras formas de valoración. Finalmente, ambas lógicas consideran la pertinencia de conceptualizar a la naturaleza como capital natural con el objetivo de captar la renta que genere. En suma, la economía verde puede entenderse como el marco general en el que opera la conservación neoliberal. Ambos conceptos no se contraponen, sino que se complementan en diferentes niveles; por ello, puede afirmarse que las estrategias de conservación neoliberales contribuyen al fortalecimiento de las lógicas de la economía verde. 


\section{El modelo de conservación estricta y los procesos de desplazamiento}

Los procesos de desplazamiento y exclusión de las poblaciones locales a favor de preservar zonas naturales no son exclusivos de la conservación neoliberal, sino que procesos similares forman parte del modelo de conservación estricto o de la fortaleza (o fortress conservation en inglés). A fines del siglo XIX se comienzan a proteger los primeros espacios naturales a través de áreas protegidas creadas bajo el "modelo de Yellowstone". ${ }^{3}$ D'Amico (2015) señala que efectivamente, Estados Unidos fue el país precursor que puso en marcha la idea de preservar grandes extensiones de tierra en su estado original como santuarios para la conservación de la naturaleza. A este modelo se lo denominó modelo de conservación estricto o de la fortaleza.

Estas primeras iniciativas de conservación respondían a intereses de las élites que demandaban espacios con naturaleza prístina para realizar sus actividades de esparcimiento u ocio (Brockington et al., 2008; D’Amico, 2015). En el centro del modelo de conservación estricto está la idea de que la conservación se puede lograr únicamente en espacios sin personas. De hecho, hasta la década de los ochenta el discurso dominante en temas de conservación consideraba necesario mantener espacios naturales fuera de la influencia humana (Durand, 2017).

Diferentes Estados alrededor del mundo adoptaron el modelo de conservación estricta a través de áreas protegidas; América Latina y el Caribe no fueron la excepción. Durante el siglo XX se extiende por la región la preocupación de conservar espacios naturales y con ello, se crean las primeras áreas protegidas (Bustamante, 2016) marcadas por una clara separación entre sociedad y naturaleza que generaron numerosos conflictos, sobre todo con comunidades locales que vieron con desconfianza la pretensión de limitar el uso de recursos que tradicionalmente venían utilizando (Brockington et al., 2008).

En el marco de la segunda Cumbre Mundial de la Tierra de 1992, varios conservacionistas comenzaron a cuestionar el paradigma de la conservación estricta, especialmente la ausencia o expulsión de los seres humanos de las áreas protegidas. A partir de esta crítica se gestó un nuevo paradigma de conservación denominado Conservación basada en comunidades ${ }^{4}$ (Caballero et al., 2016). A pesar de los esfuerzos por generar prácticas de conservación más inclusivos, lo cierto es que el modelo de conservación estricto todavía cuenta con vitalidad (D’Amico, 2015) y, como se expone en las siguientes secciones, constituye en algunos casos la base para el establecimiento de áreas protegidas privadas.

\footnotetext{
${ }^{3}$ En la literatura especializada usualmente se menciona la creación en 1872 del parque nacional Yellowstone, en Estados Unidos, como el hito que dio origen a las primeras áreas protegidas a nivel mundial. Sin embargo, como señala acertadamente Brockington et al. (2008), muchas culturas alrededor del mundo ya contaban con áreas protegidas antes del establecimiento del parque nacional Yellowstone.

${ }^{4}$ Una de las críticas a este modelo de conservación es que a pesar de reconocer la importancia social en la conservación, concibe a las poblaciones locales como agentes externos, protectores o guardianes de la naturaleza y no como parte de una misma interrelación (Durand, 2017).
}

Sociedad y Ambiente, 22, marzo-junio 2020, ISSN: 2007-6576, pp. 97-123. doi: 10.31840/sya.vi22.2082 


\section{Un sitio estratégico para la conservación: Corredor Ecológico Llanganates Sangay}

El Corredor Ecológico Llanganates Sangay (CELS) se encuentra ubicado en el centro de la región andina en las provincias de Tungurahua, Pastaza y Morona Santiago en Ecuador (Figura 1). El corredor fue establecido en el año 2002; nació como una iniciativa para el fortalecimiento de la conectividad entre el Parque Nacional Llanganates y el Parque Nacional Sangay (Ríos-Alvear y Reyes-Puig, 2015). En ese mismo año el Fondo Mundial para la Naturaleza (WWF, por sus siglas en inglés) declaró al corredor como Regalo a la Tierra, de modo que el CELS es reconocido a nivel nacional e internacional como un área prioritaria en temas de conservación (Freile y Santander, 2005).

\section{Figura 1. Ubicación del Corredor Ecológico Llanganates Sangay, Ecuador}
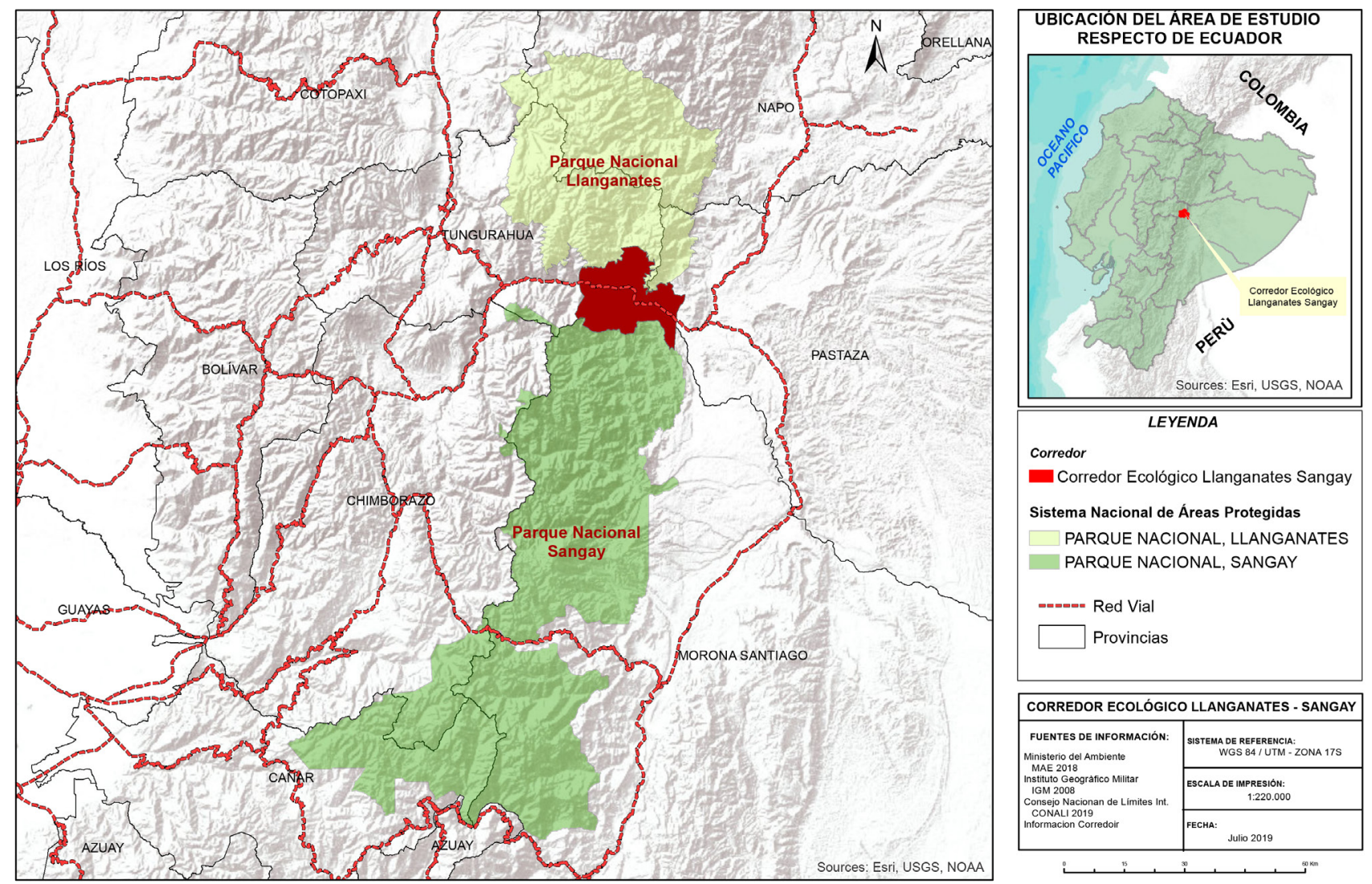

\footnotetext{
*En el mapa, la parte roja corresponde al Corredor Ecológico Llanganates Sangay, ubicado en las provincias de Tungurahua, Pastaza y Morona Santiago en Ecuador.
}

Fuente: Adaptado de Ministerio del Ambiente (2018). 
Los corredores ecológicos son estrategias propuestas para el manejo de ecosistemas, especialmente de aquellos que por sus componentes bióticos son importantes para la conservación. Con una superficie aproximada de 42856 hectáreas, el CELS alberga importantes recursos hídricos que sirven para abastecer a diferentes poblaciones, sustentar actividades agropecuarias y generar hidroelectricidad (WWF, 2013). La gestión del CELS está a cargo de las municipalidades de Baños de Agua Santa, Mera y Palora, mismas que se comprometieron a manejar la zona del corredor bajo alguna categoría de protección. La estructura administrativa para el manejo del CELS es descentralizada, lo cual permite que cada municipalidad pueda ejecutar de manera independiente sus actividades (Bajaña y Viteri, 2002).

En cuanto a la economía de los habitantes del CELS, se dedican principalmente a actividades agropecuarias, turísticas, piscícolas y forestales (WWF, 2016; Yaguache, 2014; Ríos-Alvear y Reyes-Puig, 2015). En esta zona se evidencia la producción y comercialización de productos agrícolas como mandarinas, tomate de árbol y guayaba, entre otros; servicios turísticos (senderos ecológicos, deportes acuáticos y de aventura, etcétera); piscicultura de pequeña y mediana escala, especialmente de trucha y tilapia; y venta de madera (Yaguache, 2014). Todas estas actividades han tenido, en mayor o menor medida, impactos ambientales en el CELS. No obstante, en contraposición a la expansión de actividades antrópicas que contribuyen con el deterioro ambiental, se han generado diferentes iniciativas de conservación impulsadas por diversos sectores. Esta investigación analiza el modelo de conservación que lleva a cabo una Fundación de la zona.

\section{Uso de la propiedad privada como mecanismo de conservación de la Fundación}

Esta sección primero presenta una breve introducción de las iniciativas de conservación privadas en el Ecuador; en segundo lugar, describe la estructura de la Fundación estudiada como institución; y finalmente desarrolla el modelo de conservación implementado por ésta. El levantamiento de información se realizó durante el periodo 2016-2018 a través de catorce entrevistas a actores estratégicos en el área de estudio (Tabla 1). Los actores entrevistados se dividen en tres grupos: 1) actores con incidencia directa en la gestión de la Fundación; 2) personas que han sido afectadas directa o indirectamente por la compra de tierras, y 3) especialistas con conocimiento en las dinámicas territoriales en la zona. 


\section{Tabla 1. Entrevistas realizadas a actores estratégicos del CELS}

\begin{tabular}{|c|c|}
\hline Tipo de actor & Entrevistas realizadas \\
\hline \multirow{4}{*}{$\begin{array}{l}\text { Actores con } \\
\text { incidencia en la } \\
\text { gestión de la Fun- } \\
\text { dación }\end{array}$} & $\begin{array}{l}\text { Trabajador de la Fundación 1, anónimo, noviembre de 2017, Baños } \\
\text { de Agua Santa, Ecuador. }\end{array}$ \\
\hline & $\begin{array}{l}\text { Trabajador de la Fundación 2, anónimo, noviembre de 2017, Baños } \\
\text { de Agua Santa, Ecuador. }\end{array}$ \\
\hline & $\begin{array}{l}\text { Guardaparque de la Fundación, anónimo, noviembre de 2017, Ba- } \\
\text { ños de Agua Santa, Ecuador. }\end{array}$ \\
\hline & Directivo de la Fundación, anónimo, agosto 2018, Quito, Ecuador. \\
\hline \multirow{5}{*}{$\begin{array}{l}\text { Actores afectados } \\
\text { directa o indirec- } \\
\text { tamente por la } \\
\text { compra de terre- } \\
\text { nos }\end{array}$} & $\begin{array}{l}\text { Directivo de la Asociación Ecológica Cuenca del Río Zuñag (AE- } \\
\text { CRZ) y propietario de terrenos en el CELS, anónimo, noviembre de } \\
\text { 2017, Baños de Agua Santa, Ecuador }\end{array}$ \\
\hline & $\begin{array}{l}\text { Miembro de la AECRZ y propietario de terrenos en el CELS, anó- } \\
\text { nimo, noviembre de } 2017 \text {, Baños de Agua Santa, Ecuador. }\end{array}$ \\
\hline & $\begin{array}{l}\text { Propietario de terrenos } 1 \text { en el CELS, noviembre de 2017, Baños } \\
\text { de Agua Santa, Ecuador. }\end{array}$ \\
\hline & $\begin{array}{l}\text { Propietario de terrenos } 2 \text { en el CELS, anónimo, abril de 2018, Ba- } \\
\text { ños de Agua Santa, Ecuador }\end{array}$ \\
\hline & $\begin{array}{l}\text { Ex miembro de la AECRZ y propietaria de terrenos en el CELS, } \\
\text { anónima, abril de } 2018 \text {, Quito, Ecuador. }\end{array}$ \\
\hline \multirow{5}{*}{$\begin{array}{l}\text { Especialistas en } \\
\text { las dinámicas } \\
\text { territoriales de la } \\
\text { zona }\end{array}$} & $\begin{array}{l}\text { Funcionario de World Wildlife Fund (WWF), anónimo, mayo de } \\
\text { 2017, Quito, Ecuador }\end{array}$ \\
\hline & $\begin{array}{l}\text { Investigador del Corredor Ecológico Llanganates Sangay, anóni- } \\
\text { mo, abril de 2018, Baños de Agua Santa, Ecuador }\end{array}$ \\
\hline & $\begin{array}{l}\text { Técnico del Parque Nacional Sangay, anónimo, abril de 2018, Ba- } \\
\text { ños de Agua Santa, Ecuador. }\end{array}$ \\
\hline & $\begin{array}{l}\text { Guardaparque del Parque Nacional Sangay, anónimo, abril de } \\
\text { 2018, Baños de Agua Santa, Ecuador. }\end{array}$ \\
\hline & $\begin{array}{l}\text { Especialista en áreas protegidas del Ministerio del Ambiente, anó- } \\
\text { nimo, junio de } 2019, \text { Quito, Ecuador. }\end{array}$ \\
\hline
\end{tabular}

Fuente: elaboración propia (2019). 
A pesar de que en el Ecuador existen varias iniciativas privadas que aportan a la conservación de la biodiversidad, a la fecha, solamente una de ellas se ha incorporado al Sistema Nacional de Áreas Protegidas (SNAP), ${ }^{5}$ lo cual implica un reconocimiento de ésta a perpetuidad por el Estado ecuatoriano. Otras iniciativas de conservación privadas como el caso de la Fundación analizada tienen un reconocimiento social restringido a su zona de influencia. Las áreas protegidas privadas dentro del SNAP son administradas y manejadas por su propietario en coordinación con el Ministerio del Ambiente (MAE), mientras las que se mantienen independientes son manejadas exclusivamente por su propietario. Uno de los especialistas en áreas protegidas del MAE (entrevista personal 2019; anónima), señala que pese a los numerosos esfuerzos de conservación de las iniciativas privadas que se generan a lo largo del país, pocas han mantenido algún contacto con la institución, por lo que no existe una base de datos que permita conocer cuántas existen o el número de hectáreas conservadas. Sin embargo, con la reciente declaratoria (junio 2019) de la primera área protegida privada dentro del SNAP se espera que a corto plazo más iniciativas privadas puedan tener un reconocimiento oficial.

\section{La Fundación}

La Fundación es una ONG establecida en el 2005 surge como una iniciativa de científicos y conservacionistas que buscan proteger el medio ambiente (World Land Trust, 2018). La Fundación se encuentra ubicada en el cantón Baños de Agua Santa, provincia de Tungurahua en Ecuador; tiene como objeto buscar fondos a nivel mundial para promover la conservación y el desarrollo sostenible a través de varias líneas de acción (Trabajador 1 de la Fundación, 2017, entrevista personal; anónima). La organización interna de la ONG se rige por una asamblea general, máximo órgano de la Fundación compuesto por la totalidad de los miembros y por un directorio que es el órgano de administración de la organización. La asamblea general se reúne al menos una vez al año para conocer y aprobar los informes financieros y de actividades del directorio. La mayoría de los miembros tiene profesiones a las que dedican la mayor parte de su tiempo, por lo que aportan parcialmente a las actividades de la Fundación, es decir, ejercen un papel pasivo. Sólo pocos miembros (tres o cuatro personas) de la ONG se ocupan de su administración y se encargan de tomar decisiones cotidianamente (Luna, 2019).

La mayor parte del trabajo de la Fundación se ha centrado en el CELS. De hecho, la ONG cuenta con ocho reservas privadas en esta zona, donde se prohíbe la cacería de animales y la tala de árboles, entre otras actividades que puedan afectar a los ecosistemas (Luna, 2019). A través de estas áreas protegidas, la Fundación conserva en total alrededor de 8 mil hectáreas (Trabajador 2 de la

\footnotetext{
${ }^{5}$ El Sistema Nacional de Áreas Protegidas del Ecuador está conformado por el subsistema estatal (con 53 áreas protegidas), el subsistema autónomo descentralizado (con 3 áreas protegidas), el subsistema comunitario (con 2 áreas protegidas) y el subsistema privado (con 1 área protegida: "Área Protegida Privada Bellavista").
}

Sociedad y Ambiente, 22, marzo-junio 2020, ISSN: 2007-6576, pp. 97-123. doi: 10.31840/sya.vi22.2082 


\section{Ambiente}

Fundación 2017, entrevista personal; anónima). La principal estrategia de conservación implementada por la Fundación es el establecimiento de áreas protegidas privadas. Uno de los trabajadores señala que las reservas se adquieren a través de la compra de terrenos a finqueros y campesinos y, luego de pasar por los respectivos trámites legales, se convierten en propiedad de la Fundación (Trabajador 1 de la Fundación, 2017, entrevista personal; anónima). Actualmente la Fundación cuenta con un patrimonio que supera el millón de dólares en terrenos comprados dentro del Corredor Ecológico Llanganates Sangay (Directivo de la Fundación, 2018, entrevista personal; anónima).

Para uno de los Directivos de la ONG (2018, entrevista personal; anónima), la conservación a través de la compra de tierras es una herramienta de ejecución de acciones rápidas en función de proteger determinados ecosistemas; se aprovecha la presencia de varios sectores interesados a nivel mundial en la conservación, los cuales poseen capacidad para contribuir con grandes sumas de dinero en tiempos reducidos. "Puedes encontrar varios aliados alrededor del mundo que están dispuestos a proteger el hábitat de determinadas especies. En cuestión de tres a seis meses puedes tener 30 o 50 mil dólares para comprar propiedades y cubrir los gastos legales". No obstante, el entrevistado considera que el modelo de conservación no es necesariamente sostenible, dado que luego de adquirir dinero para comprar tierras, existe poco financiamiento para gestionar y administrar los predios conservados.

Para que el modelo de conservación a través de áreas protegidas privadas sea efectivo, más allá de la adquisición de tierras, la Fundación desarrolla otras acciones y estrategias para mantener las áreas conservadas. En primer lugar, se contratan guardaparques de la zona para garantizar la seguridad y protección del sitio. Para la Fundación, contratar personas locales resultó una estrategia para facilitar sus actividades y objetivos; entre ellos: 1) que los trabajos de la Fundación tuvieran menor resistencia por parte de la comunidad; 2) aprovechar los conocimientos locales para el desarrollo de investigaciones; y 3) controlar y vigilar las reservas privadas (Luna, 2019).

En segundo lugar, la Fundación trabaja con la población local en procesos de sensibilización sobre la conservación de la naturaleza por medio de talleres, capacitaciones, entre otras modalidades formativas. Los guardaparques locales tienen el papel fundamental de incidir en el comportamiento de la población: "El trabajo más grande que realizan los guardaparques se refleja en el día a día, en las reuniones, en la cancha de vóley, es donde tienen una injerencia importante en la comunidad" (Directivo de la Fundación, 2018, entrevista personal; anónima).

En tercer lugar, la ONG busca que los procesos de desplazamiento que genera no afecten a otros espacios naturales conservados. Cuando la Fundación compra los terrenos, ésta motiva a la población local para "que invierta su dinero, que no gaste todo, si va a comprar otro terreno que no lo haga en la montaña virgen sino en zonas más bajas donde pueda desarrollar actividades sin 
dañar tanto el ambiente" (Directivo de la Fundación, 2018, entrevista personal; anónima). Por último, la organización trabaja con la comunidad para desarrollar negocios sostenibles con menor impacto ambiental como el ecoturismo o emprendimientos agroecológicos. La siembra de café es un ejemplo de esto: "sembramos un par de hectáreas con ellos, no le tenían fe, pero luego de venderlo a una cafetería de Baños se dieron cuenta que se puede tener un ingreso con menos trabajo por hectárea" (Directivo de la Fundación 2018, entrevista personal; anónima). En resumen, la ONG ejecuta un conjunto de mecanismos para la conservación de sus áreas protegidas privadas, la más importante es la conservación a través de la adquisición de propiedad privada.

Este modelo basado en áreas protegidas privadas que implementa la Fundación, conforme los planteamientos de Durand (2014), se enmarca dentro de la conservación neoliberal y reproduce el modelo de conservación estricta. Esto se evidencia en diferentes aspectos, uno de los más importantes es su relación dicotómica con la naturaleza que se expresa principalmente en: 1) la priorización de las zonas conservadas; 2) la relación con la naturaleza como algo exterior a la vida humana, como objeto por conservarse; y 3) la restricción del acceso a las áreas protegidas privadas. A continuación, se desarrolla cada uno de estos aspectos.

Con respecto a la priorización de las zonas de conservación, la Fundación selecciona espacios prístinos con poca intervención humana. ${ }^{6}$ Esta forma de relacionarse con la naturaleza fortalece la dicotomía sociedad/naturaleza, dado que reproduce la idea de que la conservación debe realizarse en espacios sin seres humanos. En cuanto a cómo relacionarse con la naturaleza, la mayoría de los miembros de la Fundación viven en zonas lejanas a las áreas protegidas privadas, por lo que sus interrelaciones son limitadas. De hecho, las zonas de conservación se han convertido, principalmente, en un laboratorio de investigación en el que se realizan estudios esporádicos para la recolección de muestras e información. No se mantiene una interrelación cotidiana con la naturaleza, lo que equivale a una relación sujeto-objeto: no se domina ni se explota la naturaleza; sin embargo, el sujeto la cerca, la posee y se apropia de ella (Luna, 2019).

Sobre la restricción del acceso a las áreas, la adquisición de áreas protegidas privadas implica la posibilidad de ejercer control sobre estos espacios. Las reservas permiten a la Fundación tener su propia gestión del terreno destinado a la conservación, mediante el control del ingreso de personas y de las actividades desarrolladas. Generalmente, se permite el ingreso de estudiantes y científicos, pero también, en menor medida, el de personas que buscan un turismo de naturaleza, en su mayoría, extranjeros. Uno de los guardaparques de la Fundación (2017, entrevista personal; anónima), señala que "Algunos miembros [de la ONG] sí son bien celosos del campo, cerca de los bosques, no les gusta que entren. Por eso abren las puertas principalmente cuando vienen estu-

\footnotetext{
${ }^{6}$ No todas las áreas protegidas privadas creadas por la Fundación generaron procesos de desplazamientos; algunas de ellas, por su aislamiento, no generaron mayores impactos sociales.
}

Sociedad y Ambiente, 22, marzo-junio 2020, ISSN: 2007-6576, pp. 97-123. doi: 10.31840/sya.vi22.2082 
diantes, botánicos, biólogos, ahí sí les gusta para que descubran algo". Desde esta perspectiva, la restricción al ingreso de las áreas protegidas está en función del beneficio que puedan aportar las personas a la Fundación.

Desde una perspectiva Norte-Sur, se observa que el modelo de conservación que promueve la ONG reactualiza una situación de privilegios con características coloniales (Luna, 2019). Muchas de las personas (estudiantes, científicos, turistas) que tienen acceso a las reservas privadas provienen de países del Norte; cuentan con capital económico y cultural convirtiéndolos en personas atractivas para la Fundación por los beneficios (económicos o conocimientos) que pueden generar. Mientras que las poblaciones del Sur (local) tienen menos acceso a los espacios conservados, ${ }^{7}$ ya que se considera que los beneficios que éstas generan para la organización son limitados. El modelo de conservación a través de la compra de predios privados se vende generalmente como una solución ganar-ganar en el que todos los actores se benefician de su implementación: En el discurso, el campesino o propietario se beneficia con el pago por sus terrenos, la ONG logra implementar su proyecto de conservación (en muchos casos rentable) y la naturaleza se beneficia de la conservación. Sin embargo, en la práctica, esta visión se encuentra, generalmente, fuera de la realidad.

Uno de los miembros de la Fundación (Trabajador 1 de la Fundación, 2017, entrevista personal; anónima) señala que en ciertas ocasiones algunas personas no respetan la propiedad privada y entran a las áreas protegidas: "hemos tenido problemas con uno que otro cazador de las comunidades que no quiere respetar la propiedad privada". También se tiene evidencia de que existe cierta deforestación, sobre todo, en las zonas bajas de las reservas. Por lo anterior, se cree que las poblaciones locales todavía dependen de los recursos naturales localizados en las zonas conservadas. No obstante, una vez que los terrenos pasan a formar parte de la Fundación, se ejerce un mayor control sobre estos espacios a través de la propiedad privada y, por esta vía de legalidad los pobladores deben buscar nuevos lugares donde realizar sus actividades para obtener su sustento. "Lo que se da ahora es que la Fundación ha comprado muchos de los terrenos que eran cercanos a las comunidades, como ya no pueden producir en estos espacios la gente ahora está yendo a otras comunidades cercanas a buscar bosques para la agricultura. Este es un fenómeno que hemos producido nosotros" (Trabajador 2 de la Fundación, 2017, entrevista personal; anónima).

En consecuencia, el establecimiento de áreas protegidas privadas opera como un mecanismo generador de procesos de desplazamiento y exclusión en la zona. En ciertos sectores, una vez que los campesinos venden sus terrenos (generalmente a precios bajos), tienen que dedicarse a otras actividades de subsistencia o buscar tierras fértiles en zonas más aisladas para poder cultivar sus productos. "Hemos visto desplazamientos en El Placer [comunidad local], una de las personas que nos

${ }^{7} \mathrm{El}$ acceso de las poblaciones locales a las áreas protegidas privadas de la Fundación no es totalmente restringido; en ciertos casos, se permite el uso de estos espacios para pequeños proyectos de turismo comunitario. 
vendió terrenos tuvo que irse hacia la zona más baja, cerca de Mera, donde compró otra propiedad para dedicarse a la agricultura" (Directivo de la Fundación, 2018, entrevista personal; anónima).

A los campesinos que históricamente se han dedicado a la agricultura les resulta difícil cambiar de actividad productiva dado que el cambio les genera inseguridad económica y la falta de educación formal los limita a la inserción en nuevas áreas de trabajo. Así pues, la compra de terrenos para el establecimiento de áreas protegidas no es una solución ganar-ganar; generalmente produce perdedores: los campesinos se quedan sin fuente de subsistencia, por tanto, suelen verse obligados a dejar su comunidad con el objeto de buscar tierras aptas para la agricultura. En este proceso de migración, los campesinos deforestan nuevas zonas para la agricultura; es decir, esta actividad de subsistencia no se erradica, sólo se desplaza a otras áreas (Luna, 2019).

Como estrategia para disminuir los impactos sociales negativos que genera la compra de tierras, especialmente los procesos de desplazamiento y el fraccionamiento de la comunidad, la Fundación ha impulsado pequeños proyectos de desarrollo vinculados al turismo comunitario y a la agricultura sostenible. Estas acciones han permitido que algunas familias generen ingresos económicos adicionales en la zona, sin tener que desplazarse a otros lugares. Sin embargo, debido a que no erradica la problemática de los procesos de desplazamiento generados, el alcance de estos proyectos es limitado.

Los recursos económicos de la Fundación vienen de distintas fuentes como ONG, personas particulares, concursos, premios, entre otros, "la principal estrategia [de conservación] es buscar fondos en base a investigaciones para luego comprar tierras. Posteriormente, vendrían otras estrategias para promover el tema ambiental" (Trabajador 2 de la Fundación, 2017, entrevista personal; anónima). Una de las dificultades de esta forma de conservar es el requerimiento de una gran cantidad de recursos económicos para comprar las tierras. A pesar de los elevados costos, uno de los trabajadores de la Fundación (Trabajador 1 de la Fundación, 2017, entrevista personal; anónima) señala que es la forma más confiable y permanente de conservar: "puedes educar a la gente o enseñar sobre la importancia de la zona, ellos van a decir voy a conservar mi propiedad, pero al momento que tienen necesidades, esto puede cambiar".

\section{Grandes patrocinadores a favor de la conservación}

La búsqueda permanente de financiamiento es imprescindible para que funcione la conservación a través de áreas protegidas privadas. Sin recursos económicos, los esfuerzos de conservación se ven seriamente limitados. En este marco, al igual que en las prácticas de conservación neoliberal, el dinero adquiere un papel central. Se privilegia el dinero sobre la conservación en la medida que 
lo segundo no se puede lograr sin lo primero. En la práctica, la conservación se ha convertido en una herramienta efectiva para la captación de financiamiento que permite a diferentes organizaciones seguir funcionando (Luna, 2019). La Fundación estudiada obtiene fondos a partir de tres estrategias principales: 1) se posiciona la importancia de conservar determinadas zonas frente a actores con grandes recursos económicos que puedan financiarlas; 2) se llevan a cabo subastas para nombrar nuevas especies descubiertas; y 3) se realizan convenios con universidades para que los estudiantes puedan hacer sus investigaciones en las áreas protegidas.

La primera estrategia de captación de fondos es la más importante para la Fundación, ya que ha generado la mayor cantidad de recursos económicos. La ONG analizada capta el interés de grandes empresas promocionando la importancia de su trabajo en conservación a través de una red de contactos a nivel internacional. Así, la Fundación consiguió importantes aportes económicos de la empresa de turismo británica llamada Naturetrek Wildlife Holidays, especializada en tours por zonas con una alta diversidad ecológica y cultural alrededor del mundo. Esta empresa realiza donaciones a organizaciones ambientales para que puedan conservar zonas con alta biodiversidad. Naturetrek donó hasta el año 2018 alrededor de 300 mil libras esterlinas a la Fundación y a World Land Trust para que, a través de estas organizaciones, se pudieran crear reservas protegidas en el CELS (Naturetrek Wildlife Holidays, 2018a). Como retribución al aporte económico de la empresa, la Fundación nombró a una de sus reservas como Naturetrek.

Mediante estas donaciones, la empresa de turismo asegura que sus clientes, la mayoría de ellos de altos ingresos económicos, puedan acceder a zonas naturales bien conservadas pagando importantes sumas de dinero. Por ejemplo, la empresa Naturetrek ofrece paquetes turísticos de 20 días a las Islas Galápagos, en Ecuador, por un precio que supera los 9 mil dólares. Si el cliente está interesado en conocer la reserva Naturetrek ubicada en el cantón Baños de Agua Santa puede solicitar que sea parte del paquete de viaje (Naturetrek Wildlife Holidays, 2018b). De manera que las donaciones que aparecen en el discurso como acciones desinteresadas a favor de la conservación, en el trasfondo sirven como mecanismo para tener acceso a espacios relativamente prístinos como el CELS, que son cada vez más escasos.

Para lograr captar el interés de las empresas y conseguir más financiamiento, la Fundación utiliza como estrategia nombrar las especies descubiertas o las áreas protegidas privadas creadas en reconocimiento a los patrocinadores. Los donantes utilizan estas acciones para promocionarse como empresas que contribuyen al cuidado del ambiente. Así, por ejemplo, la empresa Naturetrek señala en uno de sus folletos informativos, que una nueva especie de rana fue descubierta en la reserva que ayudó a financiar; la empresa afirma que: "esta nueva rana llevará el nombre de Naturetrek en reconocimiento a nuestro papel en salvar a esta especie y su hábitat" (Naturetrek 
Wildlife Holidays, 2018b: 10). La publicidad apela a la conciencia ambiental de las personas para captar potenciales compradores.

Otro caso a destacar son las donaciones realizadas por la empresa Puro Fairtrade Coffee, una empresa de Bélgica dedicada principalmente a la venta de café. La empresa destina, desde el 2005 , el $2 \%$ de sus ventas a proyectos de conservación. Lo hace a través de la organización World Land Trust, que se encarga de canalizar las donaciones para que se materialicen en apoyo a la conservación (World Land Trust, 2015a). La Fundación estudiada fue una de las organizaciones beneficiadas de las donaciones de Puro Fairtrade Coffee. Con estos aportes económicos se ha logrado conservar alrededor de 22 mil hectáreas en una de las reservas de la Fundación. En reconocimientos a estos aportes, la ONG analizada nombró dos especies descubiertas en la zona conservada en honor a la empresa belga: la rana Pristimantis puruscafeum y la orquídea Teagueia puroana (Figura 2).

Figura 2. Rana Pristimantis puruscafeum nombrada en reconocimiento a la empresa Puro Fairtrade Coffee

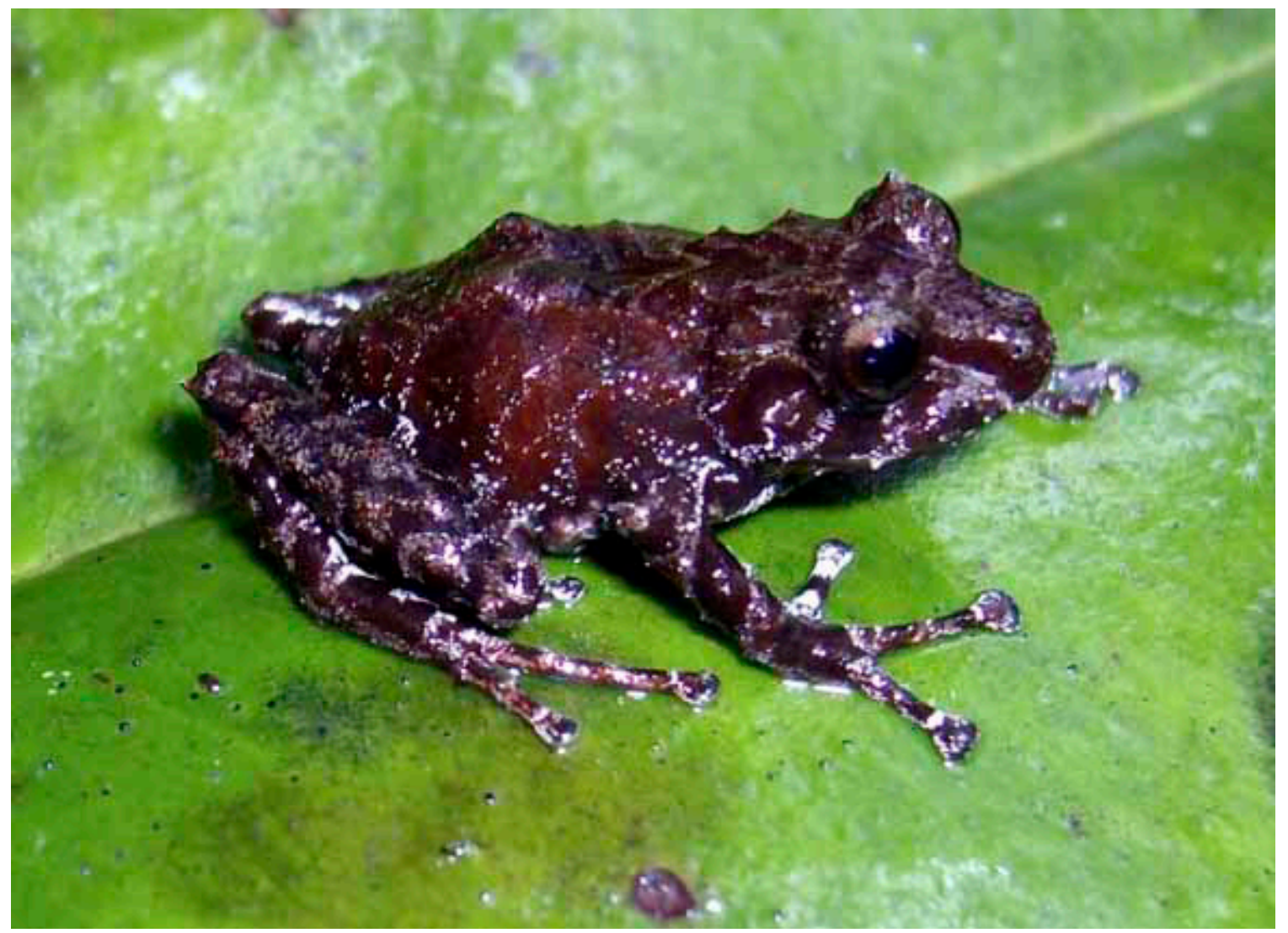

Fuente: adaptado de Reyes-Puig et al. (2014).

Sociedad y Ambiente, 22, marzo-junio 2020, ISSN: 2007-6576, pp. 97-123. doi: 10.31840/sya.vi22.2082 


\section{Socjedad Ambiente}

La empresa Puro Fairtrade Coffee, al igual que en el caso anterior, utilizó estos reconocimientos para publicitarse como una empresa comprometida con el medio ambiente, estrategia que le ha permitido captar más clientes. Adicionalmente, como estrategia publicitaria, la empresa ha realizado cortometrajes sobre las zonas que ha ayudado a conservar. Todo este material se lo puede encontrar en la página web oficial de la empresa Puro Fairtrade Coffee. ${ }^{8}$

Nominar a especies descubiertas en reconocimiento a los patrocinadores se convierte en una práctica efectiva de la Fundación para captar fondos a nivel internacional. La nominación se realiza después de la contribución económica con el fin de que el patrocinador se sienta satisfecho con su inversión y se interese en futuras donaciones. La Fundación, de forma similar a los anteriores casos expuestos, nominó una especie de rana descubierta en reconocimiento a PricewaterhouseCoopers $(\mathrm{PwC})$, una de las más importantes firmas a nivel mundial en el sector de la consultoría y auditoría que genera miles de millones de dólares en ganancias. Asimismo, nombró una flor descubierta como Blakea attenboroughii en honor a un patrocinador, Sir David Attenborough (World Land Trust, 2015b), quien es un reconocido científico que ha trabajo en temas ambientales. Otro mecanismo que utiliza la Fundación para captar fondos internacionales es la nominación directa de especies descubiertas a través de subastas. Uno de los Directivos de la Fundación (entrevista personal 2018; anónima) señala que:

Este mecanismo lo empezamos a utilizar con mayor frecuencia a través de Word Land Trust y de $R a$ inforest Trust. Lo que hacen estas instituciones es preparar una subasta donde invitan a sus contactos, gente de plata [dinero] que está interesada en ponerle nombre a, por ejemplo, una rana que es amarilla con ojos azules, un pristimantis hermosísimo, no visto ni encontrado algo parecido. Entonces, empieza la subasta con una base de 15 mil dólares americanos para arriba, el que dé más le pondremos el nombre a la ranita. El nombre puede ser el de la mamá o la abuelita, pero también el de una empresa.

Antram (s.f.) señala en la página web oficial ${ }^{9}$ de Rainforest Trust, que en celebración del aniversario número 30 de la organización, se realizó la mayor subasta de nombres de especies de la historia. El dinero recaudado en un día superó los 180 mil dólares. La subasta se realizó en Freeman's, una de las casas de subasta más antigua de Estados Unidos. En total, se subastaron doce especies descubiertas en Latinoamérica; de ellas, sólo tres especies, que provienen de las áreas protegidas privadas de la Fundación, lograron recaudar 59375 dólares. A continuación, se detalla el precio de las doce especies subastadas (Tabla 2).

\footnotetext{
${ }^{8}$ En el siguiente link (https://www.purocoffee.com/saving-the-rainforest/ ) se puede apreciar la estrategia publicitaria de Puro Fairtrade Coffee para posicionarse como una empresa verde. Recuperado el 18 de diciembre de 2019.

${ }_{9}^{9}$ Para más información consulte en el página web de Rainforest Trust Recuperado de https://www.rainforesttrust.org/species-legacy-auction-is-a-resounding-win-for-wildlife-conservation/ (última consulta 24 de diciembre de 2019).
} 


\section{Tabla 2. Lista de precios de nombres de especies subastados}

\begin{tabular}{|l|l|l|}
\hline Número de Lote & Características & Precio vendido (dólares) \\
Lote 1 & Rana ecuatoriana & 19375 \\
Lote 2 & Orquídea colombiana (a) & 13750 \\
Lote 3 & Ratón de bosque ecuatoriano & 20000 \\
Lote 4 & Rana colombiana (a) & 25000 \\
Lote 5 & Orquídea colombiana (b) & 15000 \\
Lote 6 & Salamandra panameña & 15000 \\
Lote 7 & Rana colombiana (b) & 20000 \\
Lote 8 & Orquídea ecuatoriana & 20000 \\
Lote 9 & Hormiga ecuatoriana & 13750 \\
Lote 10 & Rana panameña & 20000 \\
Lote 11 & Orquídea colombiana (c) & 15000 \\
Lote 12 & Cecílido panameño & 31250 \\
\hline
\end{tabular}

Fuente: adaptado de Freeman's (s.f.)

Las subastas para nombrar especies son mecanismos que permiten recaudar importantes sumas de dinero en nombre de la conservación. Las empresas o instituciones patrocinadoras pueden utilizar estos mecanismos para mejorar su imagen pública. Algunos patrocinadores se involucran en la conservación no sólo por su compromiso con la naturaleza, sino también por el interés de obtener publicidad (como individuos o empresas). Varias empresas se promocionan como empresas verdes ${ }^{10}$ que apoyan la conservación a través de donaciones; el objetivo es atraer clientes con afinidad a este tipo de iniciativas. Las empresas utilizan estas prácticas verdes como una estrategia de marketing para atraer clientes y aumentar las ganancias. El componente verde sirve para apelar a los consumidores a optar por una empresa comprometida con la naturaleza (Luna, 2019).

Estas prácticas se encuentran dentro de la lógica de la economía verde: posicionan pequeñas acciones como una solución a las problemáticas ambientales sin tocar temas de fondo. Así pues, se desvían del verdadero problema que es la contaminación causada por las grandes empresas. Naturetrek, por más que en el discurso se presente como una empresa verde, en la práctica promueve al año cientos de viajes que causan gran contaminación. De forma similar, Puro Fairtrade Coffee promueve una imagen verde que desvía el problema de contaminación que genera.

\footnotetext{
${ }^{10}$ Las páginas web oficiales de Naturetrek y Puro Fairtrade Coffee contienen secciones que promocionan sus acciones a favor del cuidado del ambiente (Recuperado de https://www.naturetrek.co.uk/website/sustainable_tourism.aspx y https://www.purocoffee.com/ saving-the-rainforest/orchid-mountain-reserve/). Última consulta 18 de diciembre de 2019.
} 
De hecho, la imagen que se observa en la Figura 3 resulta reveladora; por un lado, el producto se muestra alrededor de una naturaleza conservada gracias a la empresa, el título del artículo es: "Puro: café para la conservación", pero, por otro lado, al hacer un análisis más detallado, se observa como contradicción que todo el material utilizado por la empresa en la imagen es desechable. Es decir, luego de su consumo se convierte en basura que genera contaminación.

\section{Figura 3. Imagen publicitaria de Puro Fairtrade Coffee: "Puro: Coffee for conservation"}

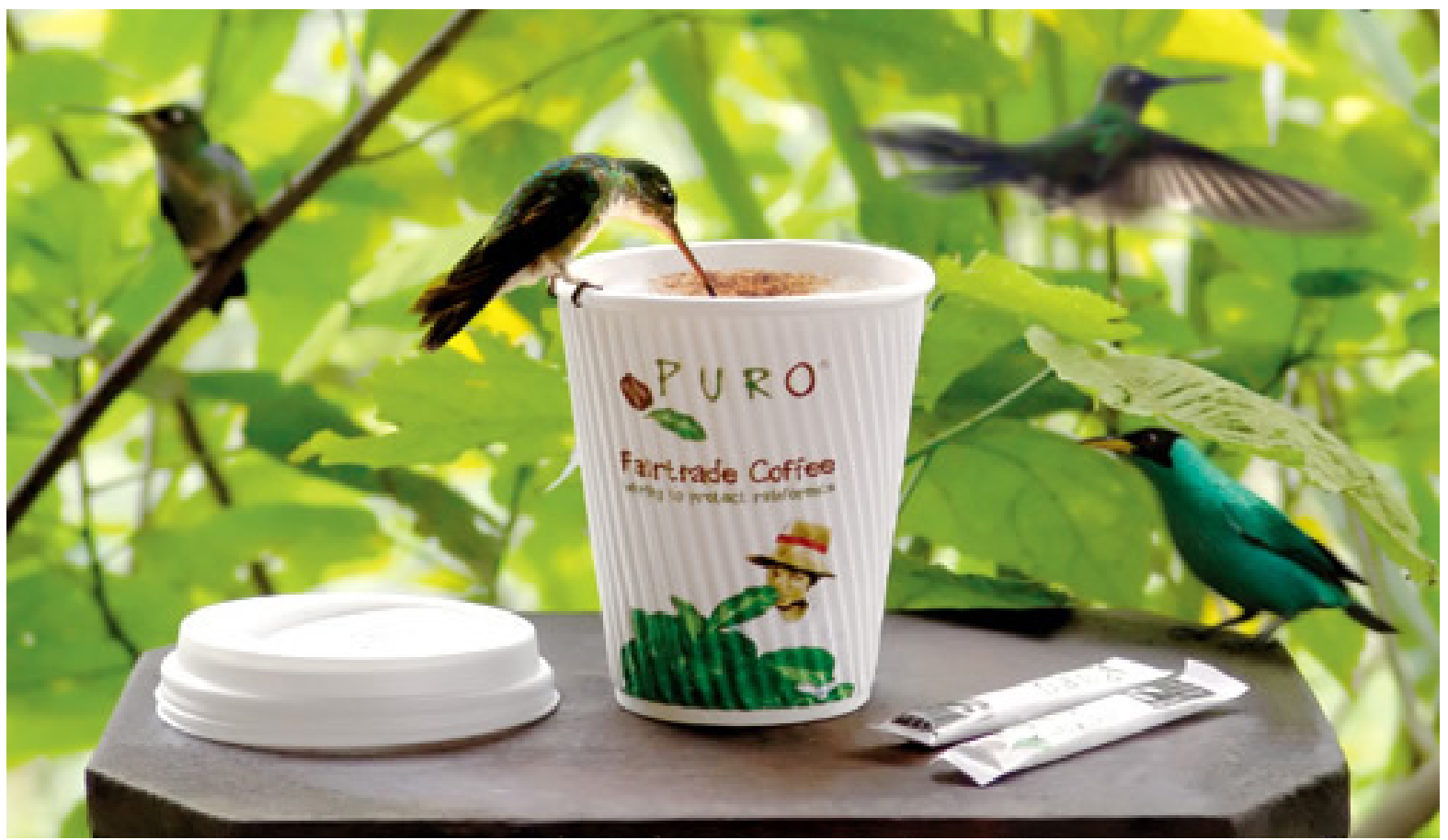

Fuente: adaptado de World Land Trust (2009).

Estas lógicas se conocen como greenwashing (lavado verde en español), término propuesto en 1986 por el ambientalista Jay Westervel para designar prácticas de empresas que a través de la difusión de información poco confiable presentan una imagen ambientalmente responsable. "Mediante el greenwashing, las empresas (o las instituciones) tratan de lavar su imagen (o nuestro cerebro) y aprovechar el prestigio comercial de lo verde publicitando sus productos (o sus políticas) como respetuosos con el medio ambiente o ecológicos, cuando no es del todo cierto" (Fanjul, 2011: s.p.). 
Los aportes a favor de la conservación que realizan empresas como Naturetrek o Puro Fairtrade Coffee son más bien simbólicos ${ }^{11}$ y no generan una disminución absoluta de los flujos de materiales y de energía, que es lo que necesita el planeta para equilibrar sus ecosistemas sino que, al contrario, la buena conciencia que esta estrategia genera a los consumidores no solamente otorga ganancias a la empresa, sino que incluso puede aumentar el consumo de viajes por el efecto rebote (rebound effect). Entonces en términos generales, la estrategia de conservación aquí expuesta puede llevar a una mayor contaminación del planeta que si no la hubiera.

Bajo esta lógica, una ONG como la Fundación estudiada sirve de puente para que empresas de todo el mundo puedan realizar sus proyectos verdes y generen publicidad que, en última instancia, aumenta sus ganancias. La Fundación es el espacio en el que las empresas o individuos pueden invertir si quieren proyectar una imagen amigable con el medio ambiente. El mejoramiento de la imagen de la empresa sirve como una estrategia de mercado más que de conservación de la naturaleza. Otra fuente de financiamiento de la Fundación, de menor escala, es el pago que realizan pequeños grupos de estudiantes para ingresar a las reservas para hacer sus investigaciones; aunque se sabe que los ingresos generados todavía son mínimos y no representan una parte importante de su financiamiento.

\section{Conclusiones}

Esta investigación realizó una caracterización del proceso de compra de tierras para la creación de áreas protegidas privadas. La conservación se ha instaurado en el discurso como una solución frente a las problemáticas ambientales. La conservación neoliberal, en particular, se ha convertido en una propuesta atractiva para diferentes sectores, que ven a este mecanismo como una forma de obtener ingresos económicos. A partir de la experiencia analizada se resumen los principales hallazgos:

1. Las prácticas de conservación impulsadas por la Fundación investigada se insertan dentro de la conservación neoliberal y reproducen las lógicas del modelo de conservación estricto. El modelo propuesto por la Fundación busca conservar espacios sin presencia humana, lugares prístinos con no (o con poca) intervención humana. Se observó que los espacios conservados por la Fundación son generalmente aislados, cercados y controlados a través de la propiedad privada, por tanto, sus usos son más restrictivos. La Fundación recurre a la compra de tierras como

\footnotetext{
${ }^{11}$ Esta investigación no pretende dejar de reconocer los esfuerzos que están realizando estas empresas en comparación con otras que generan mayores volúmenes de contaminación, sino visibilizar que las acciones que realizan no representan cambios estructurales en el sistema.
}

Sociedad y Ambiente, 22, marzo-junio 2020, ISSN: 2007-6576, pp. 97-123. doi: 10.31840/sya.vi22.2082 


\section{Ambiente}

su principal estrategia de conservación; para ello, necesita gestionar grandes sumas de dinero que provienen de importantes patrocinadores internacionales. La conservación por medio del establecimiento de áreas protegidas privadas permite a la ONG tener control de sus reservas a largo plazo. Las tierras compradas cuentan con un marco jurídico nacional e internacional que resguarda la propiedad privada. Frente a este control, las poblaciones locales del CELS no pueden hacer uso de los recursos naturales de la zona y, en consecuencia, se someten a procesos de desplazamiento. Estos procesos de apropiación de tierras y recursos ambientales en condiciones de desigualdad, pueden ser entendidos como acaparamientos verdes.

2. La centralidad del dinero es un aspecto clave en las prácticas del modelo de conservación neoliberal. Se identificó que la conservación puede convertirse en una herramienta eficaz para captar recursos económicos, especialmente, se observó que las subastas para nombrar especies son un mecanismo efectivo para captar fondos a corto plazo. En la conservación neoliberal, la preservación de la naturaleza depende de la captación de fondos: sin fondos no habría conservación y sin conservación no habría pequeños ingresos para los actores que impulsan este tipo de iniciativas. La Fundación ha logrado establecer, a partir del discurso de la conservación, alianzas con instituciones y empresas donantes internacionales que han brindado una importante suma de financiamiento. Desde esta perspectiva, la conservación como objetivo puede incluso pasar a un segundo plano, con lo cual se vuelve prioritaria la recaudación de financiamiento.

3. La compra de tierras para la creación de áreas protegidas privadas es un instrumento efectivo para generar procesos de despojo, privatización y desplazamiento de la población local. Se observó que los campesinos una vez que venden sus terrenos, generalmente a bajos costos, se ven obligados a desplazarse a otros sectores en búsqueda de tierras para la agricultura, que es su fuente de subsistencia. El caso estudiado permitió corroborar que la compra de terrenos a pobladores del CELS para el establecimiento de una de las reservas de la Fundación, generó el desplazamiento de algunas familias las cuales se vieron obligadas a dejar su casa en búsqueda de tierras para la agricultura. La compra de tierras constituye un mecanismo de desplazamiento que no recurre a formas tradicionales de violencia. En el caso estudiado, la ONG no se apropió de los predios de los campesinos a través del uso de la fuerza o por medio de tácticas de intimidación, sino que, bajo lógicas asimétricas de poder, convenció a los campesinos de vender sus tierras bajo el discurso de ganar-ganar.

4. La conservación neoliberal contribuye a la expansión de la economía verde. Se observó que varias empresas alrededor del mundo destinan fondos para proyectos de conservación con el fin de promover una imagen verde; con ella, pretenden legitimar la contaminación que causan o la usan como estrategia de publicidad para aumentar sus ventas. La experiencia analizada mues- 
tra que empresas provenientes de países del Norte otorgan importantes sumas de dinero para la creación de proyectos de conservación en países del Sur a cambio de que se reconozcan sus aportes (aunque esta intención no siempre esté explícita en el discurso de las empresas). Las ONG como la Fundación estudiada sirven de medios para que las empresas (comprometidas o no con la conservación) puedan invertir en proyectos verdes orientados a mejorar su imagen comercial. Entonces, el logo verde funciona como una estrategia efectiva para la acumulación del capital. Bajo este esquema, la conservación se convierte en un mecanismo que permite a las empresas, por un lado, seguir contaminando sin dar verdaderas soluciones a las problemáticas ambientales y, por otro lado, aumentar los niveles de ganancias económicas.

\section{Referencias}

Antram, Alex (s.f.). "Species Legacy Auction is a Resounding Win for Wildlife Conservation". $R a$ inforest Trust. Recuperado de https://www.rainforesttrust.org/species-legacy-auction-is-a-resounding-win-for-wildlife-conservation/ (última consulta 24 de diciembre de 2019).

Bajaña, Fernando y Viteri, Xavier (2002). Plan preliminar de manejo del corredor ecológico Llanganates-Sangay. Quito: Fundación Natura/Fondo Mundial para la Naturaleza/Ministerio del Ambiente/Municipio de Baños/Municipio de Mera/ Municipio de Palora.

Brand, Ulrich (2012a). "Green Economy - e Next Oxymoron? No Lessons Learned from Failures of Implementing Sustainable Development”. GAIA, 21(1), pp. 28-32.

Brand, Ulrich (2012b). "Green Economy and Green Capitalism: Some Theoretical Considerations". Ulrich Brand y Birgit Daiber (comps.), Journal Für Entwicklungspolitik, 28(3). Edition Südwind, pp. 118-137.

Brand, Ulrich y Wissen, Markus (2013). "Strategien einer Green Economy, Konturen eines grünen Kapitalismus: zeitdiagnostische und forschungsprogrammatische Überlegungen”. En Fit für die Krise? Perspektiven der Regulationstheorie. Viena-Berlin, pp. 132-148.

Brockington, Dan e Igoe, James (2006). "Eviction for Conservation: A Global Overview". Conservation and Society, 4(3), pp. 424-470.

Brockington, Dan y Duffy, Rosaleen (2011). "Introduction: Capitalism and Conservation: The Production and Reproduction of Biodiversity Conservation”. En Capitalism and Conservation. Reino Unido: Wiley-Blackwell, pp. 1-16.

Brockington, Dan; Duffy, Rosaleen, e Igoe, James (2008). Nature Unbound. Conservation, Capitalism and the Future of Protected Areas. Earthscan.

Büscher, Bram; Sullivan, Sian; Neves, Katja; Igoe, Jim, y Brockington, Dan (2012). "Towards a Synthesized Critique of Neoliberal Biodiversity Conservation”. Capitalism Nature Socialism, 2(23), pp. 4-30. 
Bustamante, Teodoro (2016). Historia de la conservación ambiental en Ecuador: volcanes, tortugas, geólogos y políticos. Editorial Abya Yala/Flacso Ecuador.

Budds, Jessica y McGranahan, Gordon (2003). "Are the Debates on Water Privatization Missing the Point? Experiences from Africa, Asia and Latin America". Environment and Urbanization, 15(2), pp. 87-113.

Caballero, Pablo; Herrera, Gonzalo; Barriozabal, Christian, y Pulido, María T. (2016). "Conservación basada en comunidad: importancia y perspectivas para Latinoamérica". Estudios Sociales, (48), pp. 337-353.

Castree, Noel (2003). “Commodifying what Nature?”. Progress in Human Geography, 27(3), pp. 273-297.

Castree, Noel (2008). "Neoliberalising Nature: The Logics of Deregulation and Reregulation". Environment and Planning A, 40, pp. 131-152.

Corson, C., MacDonald, K. I., y Neimark, B. (2013). “Grabbing ‘Green’: Markets, Environmental Governance and the Materialization of Natural Capital". Human Geography, 6(1), pp. 1-15.

Cruz, Ranulfo; Cruz, Arteminio; Cuevas, Venancio, y Ramírez, Benito (2018). "Impacto de la mercantilización de la naturaleza en la Sierra de Huautla, Morelos". Estudios Sociales, 28(51), pp. 1-23.

D’Amico, Paula (2015). "Debates sobre conservación y áreas naturales protegidas: paradigmas consolidados y nuevos horizontes". Letras Verdes. Revista Latinoamericana de Estudios Socioambientales, (18), pp. 208-226.

Durand, Leticia (2014). “¿Todos ganan? Neoliberalismo, naturaleza y conservación en México”. Sociológica, (82), pp. 183-223.

Durand, Leticia (2017). Naturalezas desiguales. Discursos sobre la conservación de la biodiversidad en México. Cuernavaca: Universidad Nacional Autónoma de México.

Fairhead, James, Leach, Melissa, y Scoones, Ian (2012). "Green Grabbing: A New Appropriation of Nature?”. Journal of Peasant Studies, 39(2), pp. 237-261.

Fanjul, Sergio (2011). "El engaño verde". El País. Recuperado de https://elpais.com/sociedad/2011/08/05/actualidad/1312495207_850215.html (última consulta 18 de diciembre de 2019).

Freeman's. (s.f.). "Auction Information. Sale 1618B. Rainforest Trust: Species Legacy Charity". Freeman's. Recuperado de https://auctions.freemansauction.com/auction-catalog/1618B (última consulta 24 de diciembre de 2019).

Freile, Juan y Santander, Tatiana (2005). "Áreas importantes para la conservación de las aves en Ecuador”. En Áreas importantes para la conservación de las aves en los Andes Tropicales: sitios prioritarios para la conservación de la biodiversidad. Quito: BirdLife/Conservation Internacional.

Giménez, Raimundo (2010). "La estrategia mundial para la conservación de la naturaleza". Encuentros en la Biología, 3(129), 31 pp. 
Gudynas, Eduardo (1993). "La privatización de la vida: América Latina ante las nuevas políticas neoliberales". Revista de la Multiversidad Franciscana de América Latina, 3.

Hernández, Enrique (2011). "Módulo 6: Gestión del Patrimonio Natural". Programa de Desarrollo de Capacidades para el Caribe. La Habana: UNESCO. Recuperado de http://whc.unesco.org/ document/107154

Igoe, Jim y Brockington, Dan (2007). "Neoliberal Conservation: A Brief Introduction". Conservation and Society, 5(4), pp. 432-449

Lander, Edgardo (2011). La economía verde: el lobo se viste con piel de cordero. Ámsterdam: Transnational Institute.

Luna, Oscar (2019). Lógicas de conservación en la cuenca del río Pastaza. Diversas formas de relacionarse con la naturaleza. Universidad Andina Simón Bolívar, sede Ecuador, Área de Estudios Sociales y Globales.

March, Hug (2013). "Neoliberalismo y medio ambiente: una aproximación desde la geografía crítica”. Documents d'Anàlisi Geogràfica, 59(1), pp. 137-153.

Meléndez, Virginia (2010). “2010: Año Internacional de la Biodiversidad”. Bioagrociencias 3(2), pp. $8-16$.

Ministerio del Ambiente. 2018. Sistemas Nacional de Áreas Protegidas. Recuperado de http:// areasprotegidas.ambiente.gob.ec/es/mapa (última consulta 3 de febrero 2020).

Moreno, Camila (2013). "Las ropas verdes del rey. La economía verde: una nueva fuente de acumulación primitiva". En Miriam Lang, Claudia López y Alejandra Santillana (coords.), Alternativas al Capitalismo/Colonialismo del Siglo XXI, Quito: Fundación Rosa Luxemburgo/ Abya Yala, pp. 63-100.

Naredo, José Manuel (1996). "Sobre el origen, el uso y el contenido del término sostenible". Cuadernos de Investigación Urbanística, (41), pp. 7-18.

Naturetrek Wildlife Holidays (2018a). "Sustainable Tourism". Naturetrek. Recuperado de https:// www.naturetrek.co.uk/about-us/sustainable-tourism (última consulta 18 de diciembre de 2019).

Naturetrek Wildlife Holidays (2018b). "News from Naturetrek's Ecuadorian Cloudforest Reserves". Naturetrek Wildlife Holidays Worldwide Newsletter.

Oviedo, Gonzalo (2013). “Áreas Protegidas, Desarrollo Y Cultura”. Letras Verdes, (2), pp. 2-4.

Reyes-Puig, Juan Pablo; Reyes-Puig, Carolina; Ramírez Jaramillo, Salomón; Pérez, María, y Yánez-Muñoz, Mario (2014). "Tres nuevas especies de ranas terrestres Pristimantis (Anura: Craugastoridae) de la cuenca alta del Río Pastaza, Ecuador". Avances en Ciencias e Ingenierías, 6(2), pp. B51-B62.

Ríos-Alvear, Gorki y Reyes-Puig, Carolina (2015). "Corredor ecológico Llanganates- Sangay: Un acercamiento hacia su manejo y funcionalidad”. Yachana, 4(2), pp. 11-21. 
UICN (Unión Internacional para la Conservación de la Naturaleza) (1980). Estrategia Mundial para la Conservación. La conservación de los recursos vivos para el logro de un desarrollo sostenido. UICN/PNUMA/WWF.

UICN (2003). Áreas Protegidas en Latinoamerica — de Caracas A Durban-. Un vistazo sobre su estado (1992-2003) y tendencias futuras. UICN.

World Land Trust (2009). "Puro: Coffee for conservation". World Land Trust. Recuperado de https://www.worldlandtrust.org/news/2009/05/puro-coffee-for-conservation/ (última consulta 18 de diciembre de 2019).

World Land Trust (2015a). "Puro Fairtrade Coffee films go to the heart of WLT's conservation work". World Land Trust. Recuperado de https://www.worldlandtrust.org/news/2015/04/puro-coffee-film-project-goes-heart-wlt-s-conservation-work/ (última consulta 18 de diciembre de 2019).

World Land Trust (2015b). "Annual Review and Accounts". World Land Trust. Recuperado de https://www.worldlandtrust.org/wp-content/uploads/2018/02/2015-annual-report.pdf (última consulta 18 de diciembre de 2018).

World Land Trust (2018). "Fundación". World Land Trust. Recuperado de https://www.worldlandtrust.org/who-we-are/partners/fundacion-ecominga/ (última consulta 18 de diciembre de 2019).

World Wildlife Fund (WWF) (2013). "Mejorando la protección del bosque Amazónico en Ecuador". World Wildlife Fund. Recuperado de http://www.wwf.org.co/?208482/mejorando-la-proteccin-del-bosque-amaznico-en-ecuador (última consulta 18 de diciembre de 2019).

World Wildlife Fund (WWF) (2016). Gira de intercambio de experiencias Corredor Ecológico Llanganates-Sangay (CELS). Quito: World Wildlife Fund.

Yaguache, Robert (2014). Plan de restauración a nivel de paisaje del corredor ecológico Llanganates Sangay. Quito: World Wildlife Fund.

Yin, Robert K. (2003). Case Study Research: Design and Methods, Londres: Sage.

Editora asociada: Minerva Arce Ibarra

Recibido: 10 julio 2019

Aceptado: 8 enero 2020

Publicado: 12 de marzo 2020 